\title{
As concepções do Direito de Ronald Dworkin e a liberdade sindical no Brasil
}

\author{
Gilberto Stürmer \\ Olga Maria Boschi Aguiar de Oliveira ${ }^{* *}$
}

\section{INTRODUÇÃO}

O presente artigo se propõe a examinar, à luz das concepções do direito propostas por Ronald Dworkin, ' o sindicalismo no Brasil do início do terceiro milênio e a (ainda ausente) liberdade sindical. A obra examinada é O Império do Direito (Law's Empire).

$\mathrm{Na}$ obra, Dworkin discute as seguintes questões, divididas em onze capítulos: o que é o direito?; conceitos de interpretação; a jurisprudência revisitada; convencionalismo; pragmatismo e personificação; integridade; integridade no direito; o common law; as leis; a constituição; e, o direito além do direito.

Inicialmente busca-se apresentar a idéia de Dworkin sobre o direito.

Posteriormente são examinadas as concepções do direito denominadas "convencionalismo", "pragmatismo jurídico" e "direito como integridade".

É traçado o panorama do sindicalismo no Brasil, bem como os conceitos de liberdade sindical. Destacam-se os motivos da ausência de liberdade sindical no Brasil, fazendo um comparativo com as três concepções do direito propostas por Dworkin.

\footnotetext{
-Advogado, Professor de Direito do Trabalho na PUCRS e na UNISINOS, Mestre em Direito pela PUCRS, Doutor em Direito do Trabalho pela UFSC.

** Coordenadora do Curso de Pós-Graduação em Direito da UFSC, Vice-diretora do Centro de Ciências Jurídicas da UFSC, Consultora INEP/MEC, SESU/MEC, CAPES e Fundação Carlos Chagas, Mestre e doutora em Direitos Sociais pela UNAM/México.

1 DWORKIN, Ronald. O Império do Direito. Tradução de Jefferson Luiz Camargo. São Paulo: Martins Fontes, 1999.
} 
Por fim, como conclusão, abordase a liberdade sindical inserindo-a nas referidas concepções do direito.

\section{O IMPÉRIO DO DIREITO}

Com efeito é importante esclarecer que, do ponto de vista objetivo, a obra de Dworkin não faz qualquer referência à América Latina ou ao Brasil. Todos os exemplos por ele apresentados referem-se aos Estados Unidos da América e à Grã-Bretanha.

A idéia é, contudo, extrair aspectos conceituais dos escritos deste importante filósofo do direito, para que, com tais idéias, se possa cotejar a situação contemporânea da realidade brasileira.

No primeiro capítulo de O Império do Direito, denominado "O que é o direito?", Dworkin traça os fundamentos básicos de todas as ilações apresentadas nos seguintes.

Registra que o direito é importante sob o ponto de vista financeiro, tratando da subsistência social e do ponto de vista moral, cuidando das questões sociais. É abordado o aspecto da fidelidade ao legislador (democracia) e de se os juízes criam ou encontram o direito.

Examina-se a simples questão de fato, trazendo como fundamentos do direito a circunstância deste ser aquilo que as instituições jurídicas decidiram no passado ou de simplesmente existir como fato. São apresentados casos do mundo real e, em relação a eles, as controvérsias sobre a natureza da lei.
Estes são os pontos destacados da obra naquilo que interessa à abordagem feita no presente artigo. Afinal, discutir liberdade sindical interessa ao mundo do direito e ao mundo dos fatos.

\section{BREVE VISÃO DAS CONCEPÇÕES DO DIREITO NA VISÃO DE RONALD DWORKIN}

Ronald Dworkin entende que as concepções do direito aprimoram a interpretação, o que proporciona o conceito de direito por ele proposto.

No referido conceito o autor apresenta três questionamentos: a) Justifica-se o suposto elo entre o direito e a coerção? Faz algum sentido exigir que a força pública seja usada somente em conformidade com os direitos e responsabilidades que decorrem das decisões políticas anteriores? b) Se tal sentido existe, qual é ele? c) Que leitura de "decorrer" - que noção de coerência com decisões precedentes - é a mais apropriada?

Dworkin chama as concepções referidas de "convencionalismo", "pragmatismo jurídico" $\mathrm{e}$ "direito como integridade". Entende que o convencionalismo é a mais vulnerável das concepções e que o pragmatismo jurídico a mais poderosa. O direito como integridade é a melhor interpretação do que fazem e dizem os estudiosos do direito.

Para o convencionalismo, o direito é o direito. Não é o que os juízes pensam ser, mas aquilo que realmente é. O convencionalismo corrige a opinião particular do leigo, para quem sempre 
existe um direito a ser aplicado. Assim, os juízes devem respeitar as convenções jurídicas em vigor na sua comunidade. Nesse contexto, a política do passado é fundamento para os direitos do presente.

O convencionalismo estrito restringe a lei de uma comunidade à extensão explícita de suas convenções jurídicas. O convencionalismo moderado entende que o direito de uma comunidade inclui tudo o que estiver dentro da extensão implícita dessas convenções.

O convencionalismo se ajusta mal às práticas jurídicas. Faz-se o cotejo do convencionalismo à teoria tridimensional do direito, de Miguel Reale. ${ }^{2} \mathrm{O}$ convencionalismo de Dworkin equivale, para Reale, ao direito como norma.

A segunda concepção de direito de Dworkin é o pragmatismo. É a mais poderosa das concepções e só pode ser vencida quando a esfera de debates se amplia para incluir também a filosofia política.

Para o pragmatismo não se justifica o elo entre direito e coerção, não há sentido ou conexão entre a exigência da força pública em conformidade com as decisões tomadas no passado e os juízes devem tomar decisões que lhes parecem melhores para o futuro da comunidade, sempre ignorando o passado. Assim, o pragmatismo é uma visão cética do direito.

Cada intérprete tem e deve ter uma concepção diferente do que uma boa comunidade. Os juízes devem decidir conforme seus próprios pontos de vista. $\mathrm{Na}$ teoria tridimensional do direito de Reale, ${ }^{3}$ o pragmatismo seria o fato, pois o fato é a própria realidade. O fato é inexorável.

Por fim, a terceira concepção do direito proposta por Dworkin é o direito como integridade.

Em relação à integridade trata-se de suas exigências, tais como eqüidade, justiça e devido processo legal adjetivo. A integridade é a virtude e destrói a idéia de equiidade política obtida através da participação da vontade de todos na decisão legislativa quando está em jogo questão de princípio. Nesses casos as decisões devem ser coerentes, não admitindo concessões. A integridade condena a incoerência e promove a autoridade moral da comunidade para "assumir e mobilizar o monopólio da força coercitiva", porque faz com que a comunidade seja fiel a um sistema de princípios identificável por cada cidadão.

Em resumo a integridade efetivamente é a resposta e a

2 Ver REALE, Miguel. Lições Preliminares de Direito. 11. ed. São Paulo: Saraiva, 1984, p. 65: Na visão do jusfilósofo brasileiro, o direito tem um aspecto normativo (ordenamento e sua respectiva ciência), um aspecto fático (aspecto fático ou em sua efetividade social e histórica), e um aspecto axiológico (direito como valor de justiça).

3 Ibidem, p. 65. 
interpretação da comunidade às outras concepções de direito. $\mathrm{Na}$ visão de Miguel Reale ${ }^{4}$ o direito como integridade seria o valor, que confere determinada significação ao fato, inclinando ou determinando a ação dos homens no sentido de atingir ou preservar certa finalidade ou objetivo.

\section{O SINDICALISMO E A LIBERDADE SINDICAL NO BRASIL}

É livre a associação em sindicato, para fins de estudo, defesa e coordenação de interesses econômicos ou profissionais de todos os que, como empregadores, empregados, agentes ou trabalhadores autônomos, ou profissionais liberais, exerçam, respectivamente, a mesma atividade ou profissão ou atividades ou profissões similares ou conexas. ${ }^{5}$ A disposição legal define o sindicato.

Analisa-se a realidade constitucional brasileira, a evolução do sindicalismo no Brasil e suas perspectivas para o futuro. $O$ fundamento conceitual da liberdade sindical encontra-se insculpido nas regras e orientações da Organização Internacional do Trabalho-OIT, criada em 1919 pelo Tratado de Versailles e da qual o Brasil é signatário desde então. Prepondera no particular, a Convenção número 87, de 1948.

A participação institucional do sindicato nos movimentos sociais revela a liberdade de ação. É no local de trabalho que as consciências se formam e, quando já formadas, exercem a cidadania plena. O sindicato é o legítimo representante de classe e as relações coletivas são destinadas à defesa dos interesses coletivos.

O interesse coletivo não é a soma dos interesses individuais, mas a sua combinação, sendo, portanto, indivisível, no sentido de que satisfaz não diversos bens destinados às necessidades individuais, mas um único bem apto a satisfazer as necessidades de uma coletividade. O objeto do sindicalismo é regular as condições de trabalho de uma categoria (de interessados, independentemente de local de trabalho ou de atividade) através das normas coletivas e exercer a atividade sindical plena, no sentido de regular os interesses gerais da classe e dos trabalhadores como um todo, aspecto não encontrado nas relações individuais.

Discute-se o constitucionalismo de valores e os mecanismos de concreção da razoabilidade e da proporcionalidade, a efetividade das normas constitucionais, em geral, e dos direitos sociais, em especial. Ainda, no que diz respeito à construção e à dogmática dos direitos fundamentais, aborda-se a inserção do trabalhador (pessoa humana) na sociedade através do seu órgão máximo de representação e de cidadania: o sindicato. Nesse contexto, há de se inserir

4 REALE, Lições.., p. 65.

5 Art. 511 da Consolidação das Leis do Trabalho. 
o direito à liberdade sindical (seja no plano individual, seja no plano coletivo), nos chamados direitos de segunda dimensão. ${ }^{6}$

6 Veja-se a propósito, SARLET, Ingo Wolfgang. A Eficácia dos Direitos Fundamentais Porto Alegre: Livraria do Advogado, 1998, p. 49: "O impacto da industrialização e os graves problemas sociais e econômicos que a acompanharam, as doutrinas socialistas e a constatação de que a consagração formal de liberdade e igualdade não gerava a garantia do seu efetivo gozo acabaram, já no decorrer do século XIX, gerando amplos movimentos reivindicatórios e o reconhecimento progressivo de direitos atribuindo ao Estado comportamento ativo na realização da justiça social. A nota distintiva destes direitos é sua dimensão positiva, uma vez que se cuida não mais de evitar a intervenção do Estado na esfera da liberdade individual, mas, sim, na lapidar formulação de C. Lafer, de propiciar um direito de participar do bem-estar social. Não se cuida mais, portanto, de liberdade do e perante o Estado, e sim de liberdade por intermédio do Estado. Estes direitos fundamentais, que embrionária e isoladamente já haviam sido contemplados nas Constituições Francesas de 1793 e 1848 (que não chegou a entrar efetivamente em vigor), caracterizam-se, ainda hoje, por outorgarem ao indivíduo direitos a prestações sociais estatais, como assistência social, saúde, educação, trabalho, etc., revelando uma transição das liberdades formais abstratas para as liberdades materiais concretas, utilizando-se a formulação preferida na doutrina francesa. É, contudo, no século XX, de modo especial nas Constituições do segundo pósguerra, que estes novos direitos fundamentais acabaram sendo consagrados em um número significativo de Constituições, além de serem objeto de diversos pactos internacionais. Como oportunamente observa P. Bonavides, estes direitos fundamentais, no que se distinguem dos clássicos de liberdade e igualdade formal, nasceram abraçados ao princípio da igualdade, entendida esta num sentido material.

Ainda na esfera dos direitos da segunda dimensão, há que atentar para a circunstância de que estes não englobam apenas direitos de cunho positivo, mas também as assim denominadas liberdades sociais, do que dão conta os exemplos de liberdade de sindicalização, do direito de greve, bem como de reconhecimento de direitos fundamentais aos trabalhadores, tais como o direito a férias e ao repouso remunerado, a garantia de um salário mínimo, a limitação da jornada de trabalho, apenas para citar alguns dos mais representativos (grifei). A segunda dimensão dos direitos fundamentais abrange, portanto, bem mais do que os direitos de cunho prestacional, de acordo com o que ainda propugna parte da doutrina, inobstante o cunho positivo possa ser considerado como marco distintivo desta nova fase na evolução dos direitos fundamentais, Saliente-se, contudo, que, a exemplo dos direitos de primeira dimensão, também os direitos sociais (tomados no sentido amplo ora referido), se reportam à pessoa individual, não podendo ser confundidos com os direitos coletivos e/ou difusos da terceira dimensão. A utilização da expressão social encontra justificativa, entre outros aspectos que não nos cabe aprofundar neste momento na circunstância de que os direitos da segunda dimensão podem ser considerados uma densificação do princípio da justiça social, além de corresponderem a reivindicações das classes menos favorecidas, de modo especial da classe operária, a título de compensação, em virtude da extrema desigualdade que caracterizava (e, de certa forma, ainda caracteriza) as relações com a classe empregadora notadamente detentora de um maior ou menor grau de poder econômico." 
Sérgio Pinto Martins define "liberdade sindical como o direito dos trabalhadores e empregadores de se organizarem e constituírem livremente as agremiações que desejarem, no número por eles idealizado, sem que sofram qualquer interferência ou intervenção do Estado, nem uns em relação aos outros, visando à promoção de seus interesses ou dos grupos que irão representar. Essa liberdade sindical também compreende o direito de ingressar e retirar-se dos sindicatos".

A liberdade sindical, significa, pois, o direito de os trabalhadores e os empregadores se associarem, livremente, a um sindicato. Todo aquele que tiver interesse profissional ou econômico a ser discutido poderá reunir-se num sindicato. Os interesses profissionais ou econômicos serão, assim, dos empregados, dos empregadores e dos trabalhadores autônomos, como se observa no art. $511 \mathrm{da}$ CLT.

Os trabalhadores do serviço público também terão o direito de livremente constituir sindicato. A exceção à regra diz respeito aos membros das forças armadas, da polícia e aos servidores ou empregados públicos de alto nível, assim considerados aqueles que têm funções com caráter decisório, ou seja, de confiança, o que poderá ser feito mediante exclusão pela legislação nacional (Convenção $n^{\circ} 151$ da OIT, de 1978 , arts. $1^{\circ}, 2^{\circ}$ e $3^{\circ}$ ). Para que haja autonomia e liberdade sindical, é preciso que exista uma forma de custeio da atividade das entidades sindicais, o que deveria ser feito por intermédio de contribuições espontâneas dos filiados e não por intermédio de contribuições compulsórias. Seria, por exemplo, a mensalidade dos sócios e a contribuição decorrente do custo da negociação coletiva."

Mozart Victor Russomano define assim a liberdade sindical: "Se os institutos jurídicos podem ser representados geometricamente, diremos, de início, que a liberdade sindical é uma figura triangular. $\mathrm{Na}$ verdade, ela é formada, conceitualmente, de três partes distintas, que se tocam nas extremidades, dando-nos idéia de um perfeito triângulo jurídico".

Não se pode falar em liberdade sindical absoluta sem se admitir que exista, em determinado sistema jurídico, sindicalização livre, autonomia sindical e - em nosso juizo - pluralidade sindical. Por outras palavras: a liberdade sindical pressupõe a sindicalização livre, contra a sindicalização obrigatória; a autonomia sindical, contra o dirigismo sindical; a pluralidade sindical, contra a unicidade sindical.

É essa a posição adotada pela grande maioria dos escritores estrangeiros, inclusive Rouast e Paul Durand, na França. Não foi outra a razão pela qual, na Itália, Ferrucio Pergolesi e Francesco SantoroPassarelli definiram-na como uma 
'liberdade complexa'. Se tomarmos a liberdade sindical no seu conceito mais amplo, necessariamente encontraremos, no fundo desse instituto, aquelas três idéias básicas, sem as quais não existe liberdade plena, nem para o sindicato, nem para os trabalhadores que nele encontram os pulmões da sua vida profissional."

Com efeito, como já foi dito, quando se fala em "liberdade sindical", não se pode olvidar da Convenção $\mathrm{n}^{\circ} 87 \mathrm{da}$ Organização Internacional do Trabalho (OIT). Este órgão, do qual o Brasil é signatário (embora não tenha ratificado a referida Convenção), delibera, discute e determina regras e condições individuais e coletivas de trabalho aos países filiados.

\section{LIBERDADE SINDICAL E CONVENCIONALISMO}

Por que, à luz do convencionalismo, não há liberdade sindical no Brasil?

Como dito anteriormente, a Convenção $\mathrm{n}^{\circ} 87$ trata exatamente da "liberdade sindical", propugnando, dentre outros aspectos, o regime pluralista, ou seja, a possibilidade de criação de mais de um sindicato da mesma categoria econômica e/ou profissional na mesma base territorial. No Brasil, o princípio adotado é o da unicidade sindical (art. $8^{\circ}$, II, da Constituição Federal). A regra entra em choque com o caput e o inciso I do mesmo artigo, que vislumbram um sistema livre para o sindicalismo.

Também não se enquadram no conceito de liberdade sindical outros comandos previstos no ordenamento jurídico pátrio.

A Constituição da República assegura o direito de greve (art. $9^{\circ}$ ). Entretanto, a legislação infraconstitucional que trata da matéria (Lei $\mathrm{n}^{\circ}$ 7.783/89) limita o referido direito.

Determina-se a participação dos trabalhadores nas empresas (art. 11 da Constituição Federal). Este comando, contudo, não é observado no país do ponto de vista prático. Ademais, entra em choque com o artigo $8^{\circ}$, inciso VI, que determina a participação dos sindicatos nas negociações coletivas de trabalho.

Foram mantidas, ainda, as regras corporativistas da contribuição sindical compulsória (art. $8^{\circ}$, IV, da Constituição Federal c/c art. 581 da CLT), do poder normativo da Justiça do Trabalho (art. $114, \S 2^{\circ}$, da Constituição Federal) e do enquadramento sindical por categoria (art. 570 da CLT).

Efetivamente não há liberdade sindical no Brasil.

\section{LIBERDADE SINDICAL $E$ PRAGMATISMO JURÍDICO}

O pragmatismo é uma visão cética do direito. O sindicalismo brasileiro contemporâneo também é cético.

8 RUSSOMANO, Mozart Victor. Princípios Gerais de Direito Sindical. 2.ed. Rio de Janeiro: Forense, 1998, p. 54-66. 
Não importa como cresceu e floresceu o sindicalismo no Brasil. Não interessam aos pragmáticos, aspectos como intervenção, como fascismo e corporativismo. A realidade atual é o que deve ser considerado.

Neste contexto, fatores como a globalização, a flexibilização das condições de trabalho, o desemprego estrutural, a mudança de paradigmas das relações sociais e trabalhistas, as crises sociais e econômicas mundiais e brasileiras e, a partir de tais circunstâncias, a realidade de que os fundamentos básicos e históricos do sindicalismo (melhores condições de trabalho e melhores salários) têm sido trocados por um fundamento real (manutenção do emprego), são o que realmente têm importância.

É importante registrar que no Brasil existem aproximadamente dezenove mil sindicatos, dos quais os efetivamente representativos talvez não sejam mil. Esta realidade, claramente existe em função da inexistência de liberdade sindical. Em um ambiente de pluralismo, onde não existe contribuição sindical compulsória, indiscutivelmente sobreviverão apenas aqueles sindicatos que realmente representam a sua categoria.

No exame do fato social não é demais lembrar as centrais sindicais que, apesar de não serem órgãos de direito no sindicalismo nacional e não terem a prerrogativa de representatividade de classe e de negociação coletiva de trabalho, têm o real valor da sociedade, mantendo-se única e exclusivamente por interesse das classes que representam. Falar de centrais sindicais denota, inclusive, uma simbiose entre pragmatismo e integridade.

\section{LIBERDADE SINDICAL E DIREITO COMO INTEGRIDADE}

As classes seriam melhor representadas em um âmbito de liberdade sindical. Como dito acima, a existência de centrais sindicais é prova cabal e inequívoca de que as relações trabalhistàs têm melhor trânsito em um regime de liberdade sindical. E é assim que as centrais têm valor da sociedade, inserindo-se na concepção do direito como integridade.

Ao examinar-se a origem do sindicalismo no Brasil, pretende-se refletir e discutir se e por que, o sindicalismo emergiu a partir dos movimentos sociais ou por imposição estatal. A partir desta premissa, buscase resposta para o seguinte problema: Já houve liberdade sindical no Brasil? Há liberdade sindical no Brasil? Em que medida o sindicalismo, regulado essencialmente pela Constituição Federal, tem condições e dinamismo para adequar-se aos movimentos sociais? Qual é o futuro do sindicalismo, e conseqüentemente da liberdade sindical no Brasil?

Em um regime de liberdade sindical plena, mais trabalhadores estarão inseridos no contexto de busca de melhores condições de vida, na medida em que o sindicato deverá ser efetivamente um representante de classe, sob pena de desaparecer. 
A partir da liberdade sindical plena e da maior inserção dos trabalhadores nos sindicatos, a sociedade terá maiores resultados, diminuindo a desigualdade social.

\section{CONCLUSÃO}

1. Em O Império do Direito, Dworkin não faz qualquer alusão à América Latina ou ao Brasil.

2. No exame de casos reais não se tratou de sindicalismo. Todavia, ao elaborar conceitos, Dworkin citou aspectos relativos às relações de trabalho e a acidentes de trabalho.

3. O fundamento para a utilização da obra de Dworkin para o cotejo com o princípio da "liberdade sindical", inexistente no Brasil, é filosófico. A abordagem conceitual do direito e, principalmente as concepções de direito apresentadas pelo autor, se enquadram no exame da matéria.

4. As concepções de direito apresentadas em $O$ Império do Direito são as seguintes: "convencionalismo", "pragmatismo jurídico"e "direito como integridade".

5. O convencionalismo trata das regras aplicáveis à comunidade. Trazse a teoria tridimensional do direito de Miguel Reale, onde o direito é fato, valor e norma. O convencionalismo equivaleria à norma.

6. O pragmatismo trata da realidade. $\mathrm{O}$ que ocorre no seio da sociedade é a visão e interpretação que o juiz deve ter desta realidade. $\mathrm{Na}$ teoria tridimensional do direito, o pragmatismo corresponde ao fato.

7. O direito como integridade trata da axiologia. Aborda o valor emprestado pela sociedade a aspectos como eqüidade, justiça e outros. Assim, para a teoria tridimensional do direito, a integridade é o valor.

8. O sindicalismo é a reunião de interessados (trabalhadores ou empregadores) para fins de representatividade de classe e negociação coletiva de trabalho.

9. A liberdade sindical, à luz da Convenção 87 da Organização Internacional do Trabalho - OIT, pretende um sindicalismo sem qualquer intervenção estatal na atividade e na organização sindical.

10. No Brasil não há liberdade sindical. Aspectos constitucionais e legais, tais como a unicidade sindical, a contribuição sindical compulsória, a inexistência de representatividade de trabalhadores nas empresas, o poder normativo da Justiça do Trabalho, o enquadramento sindical por categoria e as restrições ao direito de greve, deixam clara esta realidade.

11. A ausência de liberdade sindical no Brasil está exposta na concepção do direito denominada convencionalismo.

12. O pragmatismo também registra esta realidade: $\mathrm{O}$ fato social pressiona a pretensão à liberdade sindical.

13. Por fim, como pretensão social para uma sociedade melhor, mais justa, eqüitativa e ética, a abordagem da liberdade sindical à luz da concepção do direito como integridade. 


\section{REFERÊNCIAS}

DWORKIN, Ronald. O Império do

Direito. Tradução Jefferson Luiz Camargo. São Paulo: Martins Fontes, 1999.

MARTINS, Sergio Pinto. Direito do Trabalho. 12.ed. SãoPaulo:Atlas, 2000. REALE, Miguel. Lições Preliminares de Direito. 11.ed. São Paulo: Saraiva, 1984.
RUSSOMANO, Mozart Victor. Principios Gerais de Direito Sindical. 2.ed. Rio de Janeiro: Forense, 1998.

SARLET, Ingo Wolfgang. A Eficácia dos Direitos Fundamentais. Porto Alegre: Livraria do Advogado, 1998. 